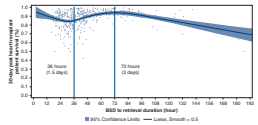

\section{PROLONGATION OF TIME FROM BRAIN \\ DEATH TO \\ RETRIEVAL IS \\ BENEFICIAL TO THE \\ DONOR HEART}

To the Editor:

We were fascinated to read the article by Jawitz and colleagues $^{1}$ on the effect of time from brain death to retrieval of donor hearts and the lack of any linkage to poor outcome. They rightly discuss the ongoing shortage of good donor hearts and the concerns raised in previous small series that there might be a continuing deterioration of myocardial tissue following the insult of brain death. Their conclusions reassure the heart transplant community that delayed retrieval does little harm.

But, in the setting of the donor heart shortage, a more valuable index to examine is heart utilization. We did a similar exercise with UK national transplant data, and showed not only a better outcome (in terms of 30-day survival) if retrieval was delayed from the time of brain death, but also better utilization; that is, more likely acceptance of the offered donor heart, and so a greater overall benefit, ${ }^{2}$ although our article was curiously not cited. Our observation is entirely in keeping with the

\footnotetext{
The Editor welcomes submissions for possible publication in the Letters to the Editor section that consist of commentary on an article published in the Journal or other relevant issues. Authors should: • Include no more than 500 words of text, three authors, and five references. • Type with double-spacing. • See http://jtcs.ctsnetjournals.org/ misc/ifora.shtml for detailed submission instructions. • Submit the letter electronically via jtcvs.editorialmanager.com. Letters commenting on an article published in the JTCVS will be considered if they are received within 6 weeks of the time the article was published. Authors of the article being commented on will be given an opportunity of offer a timely response ( 2 weeks) to the letter. Authors of letters will be notified that the letter has been received. Unpublished letters cannot be returned.
}

literature on the benefits of careful donor management. They kindly cited a 2007 article on a rat model of brain death, when restoration of mean arterial blood pressure with a vasoconstrictor not only reduced proinflammatory cytokine levels but also was linked to better gas exchange. ${ }^{3}$ But there are a wealth of clinical observations on the benefit of a focused donor care package ${ }^{4}$ and we now know the advantages of not going for early retrieval. In our series, the rate of utilization increased progressively out to 48 hours after brain death, and then remained stable. The 30-day survival posttransplant continued to improve out to 72 hours after brain death, when it began to fall off again (Figure 1).

Another limitation of the article by Jawitz and colleagues $^{1}$ is that they took as the starting point, the declaration of brain death. This might be easily collected, but is potentially distant from actual clinical and physiological events. We had access to records of the time of fixed, dilated pupils, which was a median of 12 hours (with a very wide spread) from the actual declaration. We believe the use of this clinical time point to be of much more relevance than the timing of declaration, often linked to availability of personnel and administrative timetables rather than real events.

The core message of both articles is the same; only after considerable delay is the outcome worsened. If you take into account the differences in starting point (and we believe ours to be much more relevant) the figure from our article (Figure 1) is remarkably similar to Figure 2 from Jawitz and colleagues, with 2 inflection points. ${ }^{1}$ Donor physiology is the same around the world.

We emphasize this fundamental, practical message: Teams should not be concerned about delay (at least for 60-72 hours) but rather take the vital opportunity to optimize donor care and allow the immediate, postbrain death storm to subside.

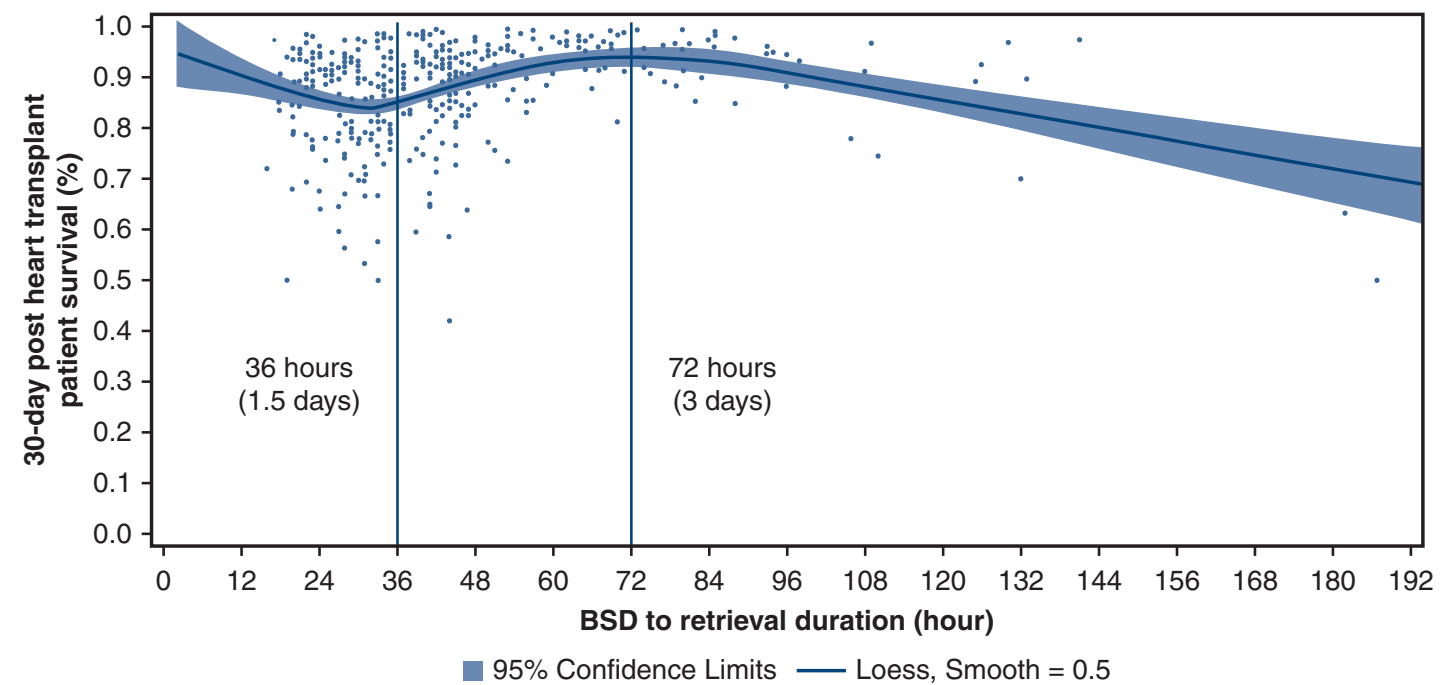

FIGURE 1. Two inflections in relation between time from brain stem death $(B S D)$ and 30-day survival. 
The authors reported no conflicts of interest.

The Journal policy requires editors and reviewers to disclose conflicts of interest and to decline handling or reviewing manuscripts for which they may have a conflict of interest. The editors and reviewers of this article have no conflicts of interest.
John H. Dark, $M D^{a}$

Jenny Mehew, $P h D^{b}$

Rajamiyer Venkateswaran, MD, FRCS-Cth

${ }^{a}$ Translational and Clinical Research Institute Faculty of Medical Sciences

Newcastle University

Newcastle upon Tyne, United Kingdom

${ }^{b}$ Statistics and Clinical Studies

National Health System Blood and Transplant

Bristol, United Kingdom

${ }^{c}$ Transplant Unit, Manchester University Foundation Trust, Wythenshawe Hospital, Manchester, United Kingdom

\section{References}

1. Jawitz OK, Raman V, Barac YD, Anand J, Patel CB, Mentz RJ, et al. Influence of donor brain death duration on outcomes following heart transplantation: a United Network for Organ Sharing Registry analysis. J Thorac Cardiovasc Surg. 2020; 159:1345-53.

2. Dimarakis I, Banner NR, Rushton S, Wong HSE, Berman M, Howell N, et al. The interval between brainstem death and cardiac assessment influences the retrieval of hearts for transplantation. Eur J Cardiothorac Surg. 2018;53:1135-43.

3. Avlonitis VS, Wigfield $\mathrm{CH}$, Golledge HDR, Kirby JA, Dark JH. Early hemodynamic injury during donor brain death determines the severity of primary graft dysfunction after lung transplantation. Am J Transplant. 2007;7: 83-90.

4. Abuanzeh R, Hashmi F, Dimarakis I, Khasati N, Machaal A, Yonan N, et al. Early donor management increases the retrieval rate of hearts for, transplantation in marginal donors. Eur J Cardiothorac Surg. 2015;47:72-7.

https://doi.org/10.1016/j.jtcvs.2020.06.127

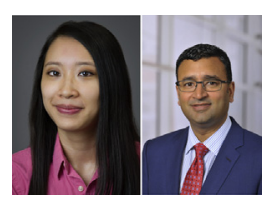

REPLY: RIDING OUT THE STORM

\section{Reply to the Editor:}

As the demand for donor hearts continues to increase and the supply remains stalwartly low, Dark and colleagues $^{1}$ have not only agreed with Jawitz and colleagues ${ }^{2}$ that donor hearts with increased duration of donor brain death times do not have a decrease in recipient survival but actually suggest that purposefully waiting longer can perhaps allow for greater rates of organ use. Based on previous papers from their institution, one a review of the heart transplanted from the UK Transplant registry, Dark and colleagues concluded that optimizing medical care while waiting up to 48 hours for donor hearts
Dr Mokadam is a consultant for Medtronic, Abbott, SynCardia, and Carmat. Dr Le reported no conflicts of interest.

The Journal policy requires editors and reviewers to disclose conflicts of interest and to decline handling or reviewing manuscripts for which they may have a conflict of interest. The editors and reviewers of this article have no conflicts of interest.

rejected for impaired function to recover could allow these hearts to eventually be transplanted.

Reperfusion injuries caused by a proinflammatory milieu induced by brain death can be managed and allow for recovery times, allowing more hearts to not only be considered but also transplanted. ${ }^{4}$ The subsequent time period afterwards should involve optimizing donor care and patience. With the current scarcity of donor hearts, this is an alluring idea. However, the authors do caution after a certain time period (60-72 hours was mentioned), the organ has achieved its maximal recovery and waiting longer will not be beneficial.

The guidance provided by these studies and the resulting responses is helpful as we navigate a world with more sickly and geriatric patients requiring heart transplantation and a limited supply of organs. ${ }^{5}$ Expanding the acceptable criteria for donor hearts even beyond what Jawitz and colleagues recommended would open unexplored avenues for helping even more of those in need. The next logical step requires more studies to investigate the long-term clinical outcomes of the recipients who have received these recovered hearts-not only recipient survival and donor use rates, but studies comparing the function, complications, and duration of these "extended-criteria" hearts post-transplant. We may see the rays of hope for transplanting even more patients after riding out the storm.

Anh-Thu Le, MD

Nahush A. Mokadam, MD

Division of Cardiac Surgery

The Ohio State University Wexner Medical Center Columbus, Ohio

\section{References}

1. Dark J, Mehew J, Venkateswaran R. Letter to the editor: prolongation of time from brain death to retrieval is beneficial to the donor heart. J Thorac Cardiovasc Surg. 2021;161:e311-2.

2. Jawitz OK, Raman V, Barac YD, Anand J, Patel CB, Mentz RJ, et al. Influence of donor brain death duration on outcomes following heart transplantation: a united network for organ sharing registry analysis. J Thorac Cardiovasc Surg. 2020;159: 1345-53.e2.

3. Dimarakis I, Banner NR, Rushton S, Wong HSE, Berman M, Howell N, et al. The interval between brainstem death and cardiac assessment influences the retrieval of hearts for transplantation. Eur J Cardiothorac Surg. 2018;53:1135-43.

4. Avlonitis VS, Wigfield CH, Golledge HD, Kirby JA, Dark JH. Early hemodynamic injury during donor brain death determines the severity of primary graft dysfunction after lung transplantation. Am J Transplant. 2007;7:83-90. 